\title{
BMJ Open Cost of managing atonic postpartum haemorrhage with uterine balloon tamponade devices in public health settings of Maharashtra, India: an economic microcosting study
}

\author{
Siddesh Sitaram Shetty (D) , ${ }^{1}$ Kusum Venkobrao Moray (D) , \\ Himanshu Chaurasia (D) , ${ }^{1}$ Beena Nitin Joshi (D) ${ }^{2}$
}

To cite: Shetty SS, Moray KV, Chaurasia $\mathrm{H}$, et al. Cost of managing atonic postpartum haemorrhage with uterine balloon tamponade devices in public health settings of Maharashtra, India: an economic microcosting study. BMJ Open 2021:11:e042389. doi:10.1136/ bmjopen-2020-042389

- Prepublication history and additional material for this paper is available online. To view these files, please visit the journal online (http://dx.doi.org/10. 1136/bmjopen-2020-042389)

Received 03 July 2020

Revised 13 January 2021

Accepted 10 February 2021

Check for updates

(C) Author(s) (or their employer(s)) 2021. Re-use permitted under CC BY-NC. No commercial re-use. See rights and permissions. Published by BMJ.

${ }^{1}$ Regional Resource Hub for Health Technology Assessment in India, Indian Council of Medical Research-National Institute for Research in Reproductive Health, Mumbai, India

${ }^{2}$ Department of Operational Research, Indian Council of Medical Research-National Institute for Research in Reproductive Health, Mumbai, India

Correspondence to

Dr Beena Nitin Joshi; bjoshithane@gmail.com

\section{ABSTRACT}

Objective Postpartum haemorrhage ( $\mathrm{PPH})$ is the worldwide leading cause of preventable maternal mortality. India offers free treatment for pregnancy and related complications in its public health facilities. Management with uterine balloon tamponade (UBT) is recommended for refractory atonic PPH cases. As part of health technology assessment to determine the most cost-effective UBT device, this study estimated costs of atonic PPH management with condom-UBT, Every Second Matters (ESM) UBT and Bakri balloon UBT in public health system of Maharashtra, India.

Design Health system cost was estimated using primary economic microcosting, data from Health Management Information System and published literature for event probabilities.

Settings Four public health facilities from the state of Maharashtra, India representing primary, secondary and tertiary level care were chosen for primary costing. Outcome measures Unit, package and annual cost of atonic PPH management with three UBT devices were measured. This included cost of medical treatment, UBT intervention and $\mathrm{PPH}$ related surgeries undertaken in public health system of Maharashtra for year 20172018.

Results Medical management of atonic PPH cost the health system US\$37 (95\% Cl 29 to 45) per case, increasing to US\$44 (95\% Cl 36 to 53) with condom-UBT and surgical interventions for uncontrolled cases. Similar cost was estimated for ESM-UBT. Bakri-UBT reported a higher cost of US\$59 (95\% Cl 46 to 73) per case. Overall annual cost of managing 27915 atonic PPH cases with condom-UBT intervention in Maharashtra was US\$1 226 610 (95\% Cl 870250 to 1581596$)$.

Conclusions Atonic PPH management in public health facilities of Maharashtra with condom-UBT, ESM-UBT or Bakri-UBT accounts to $3.8 \%, 3.8 \%$ or $5.2 \%$ of the state's annual spending on reproductive and child health services. These findings can guide policy-makers to include PPH complication management in publicly financed health schemes. Economic evaluation studies can use this evidence to determine cost effectiveness of UBT in Indian settings.
Strengths and limitations of this study

- To our knowledge, this is the first study from India comprehensively assessing public health system costs for overall management of atonic postpartum haemorrhage (PPH) with medical interventions, uterine balloon tamponade (UBT) and surgical management across all public healthcare levels in the state.

- The study uses clinical effectiveness evidence of individual UBT devices to determine health system costs.

- As disaggregated Health Management Information System data in the study setting was not available for PPH, literature-based event probability estimates from the Indian context were relied on to estimate costs.

- An assumption was made that for a particular UBT device, all eligible cases would receive only that particular UBT across all facilities.

\section{INTRODUCTION}

The global shift towards Universal Health Coverage indicated by Sustainable Development Goals (SDG) needs robust financing mechanisms. To achieve desired targets, evidence informed by costing studies can be vital to support financing decisions. Information on cost enables improved resource allocation, thus strengthening policy measures to attain highest value for a given investment. A key priority under the SDG health goal is reduction of global maternal mortality levels to less than 70 per 100000 live births by year 2030. Evidence confirms women's health to be associated with development and economic performance of a country. ${ }^{1}$ A marginal health investment at lower Gross Domestic Product (GDP) levels seen commonly in low or low-middle income countries is found to have higher effects on health outcomes. ${ }^{2}$ 
Improved maternal health not only reduces household healthcare expenditure, but is also associated with longterm economic benefits to the society.

In spite of a low spending of $1 \%$ of GDP on public health expenditure, India has managed to reduce maternal mortality ratio down to 122 per 100000 live births by the year 2015-2017, largely attributed to reforms such as institutionalisation of deliveries, provisioning of free cashless services to pregnant women and addressing social determinants of health. ${ }^{3-5}$ Despite ongoing efforts, India still accounts for nearly one-tenth of all maternal deaths globally with haemorrhage as the leading cause. ${ }^{6}$ Postpartum haemorrhage (PPH) accounts for more than two-third of all global maternal deaths due to bleeding. ${ }^{78}$ $\mathrm{PPH}$ is defined as maternal blood loss of $500 \mathrm{~mL}$ or more within 24 hours after delivery and affects nearly 3\%-6\% of all women giving birth in India. ${ }^{9}$ Atony of uterus is the most common PPH type responsible for nearly $80 \%$ of all cases. $^{10}$

Indian guidelines base PPH management on principles of treatment for shock, cause-specific PPH management and patient stabilisation before referral to higher facilities. ${ }^{11}$ India has initiated standardisation of Labour Rooms under the 'Dakshata' initiative thus equipping delivery rooms to provide comprehensive care at all times. In accordance with the WHO guideline for atonic PPH management, uterotonics remain the mainstay of treatment in India. ${ }^{12}$ Haemodynamic stabilisation and supportive resuscitation measures are expected to be kept ongoing. Use of uterine balloon tamponade (UBT) device is recommended if uterotonic agents fail in controlling atonic PPH bleeding. At primary level in India, all atonic PPH cases are expected to be provided medical management and UBT intervention to stabilise and control bleeding before referral to higher facility for observation or further interventions. Cases uncontrolled after UBT insertion at secondary or tertiary level may require B-Lynch compression suturing, stepwise devascularisation surgery (uterine, or internal iliac artery ligation) or other procedures depending on availability of expertise and health infrastructure. Hysterectomy, a lifesaving procedure may be indicated after failed conservative measures or directly after UBT insertion based on patient response. Obstetric intensive care unit (ICU) admission may be needed for observation or managing complications due to PPH.

UBT intervention for atonic PPH is a relatively simple life-saving technique and can be used even in low resource settings with limited provisions for surgery, blood transfusion or referral mechanisms. UBT technique is clinically effective in controlling PPH bleeding and reduces need for further surgical interventions. ${ }^{13}$ Timely use of UBT device can potentially be cost saving by improving maternal morbidity and mortality outcomes. Multiple UBT devices specifically designed, assembled or modified for use in PPH management are currently available. Being economical, an assembled condom-UBT device is the recommended standard of care (SOC) for atonic
PPH management in India. ${ }^{14}$ In the state of Maharashtra where this study was undertaken, apart from the recommended condom-UBT device, Bakri balloon and Every Second Matters (ESM)-UBT, two ready to use sterile packed devices made available by non-governmental organisations are used across different public health settings. ${ }^{15-17}$ The three UBT devices have certain distinct features giving each an advantage over the other. Literature reports varying clinical effectiveness and price for these UBT devices. Table 1 shows distinct characteristics of these three UBT devices used in atonic PPH management, collated from a literature review undertaken separately (online supplemental table 1 ).

Under India's flagship Pradhan Mantri Jan Arogya Yojana (PMJAY) public health insurance scheme, a woman is entitled to cashless treatment package cost of US $\$ 178$ (rupees 11 500) for high-risk vaginal deliveries and all caesarean sections. Evidence suggests that despite improved maternal outcomes with publicly sponsored schemes, extent of out-of-pocket expenditure for institutional delivery remains high especially with pregnancy complications. ${ }^{18}$ At present, the existing packages do not cover the postpartum PPH complication and there is no documented health system cost available for management of this condition. The Ministry of Health and Family Welfare, Government of India is assessing the most cost-effective UBT device for atonic PPH management in the public health system given the emerging evidence for relatively low cost ESM-UBT alternative. ${ }^{19-21}$ The policy decision to make a UBT device available for PPH management across health facilities will have associated cost and health outcome implications. This study aimed to calculate public health system cost of atonic PPH management with SOC, that is, condom-UBT recommended by the 2015 Indian guidelines for PPH management with similar projections for ESM-UBT and another globally used Bakri-UBT device. $^{15}$

\section{METHODS}

This costing study was part of a Health Technology Assessment project to evaluate the most cost-effective UBT device for atonic PPH management in India. An economic costing from the health system perspective using primary bottom-up microcosting, data from Health Management Information System (HMIS) and literature review for event probabilities were used to determine and compare unit, package and annual cost of atonic PPH management with condom-UBT, ESM-UBT and Bakri balloon (Bakri-UBT) devices in public health facilities of Maharashtra, India. State health department administrative approvals and consent from respective health facility authorities were obtained before undertaking the study.

\section{Patient and public involvement}

There was no patient or public involvement in this study design, conduct or reporting of this study and hence no consent was obtained. 
Table 1 Characteristics of uterine balloon tamponade (UBT) devices used commonly for atonic postpartum haemorrhage (PPH) management in India

\begin{tabular}{|c|c|c|c|}
\hline UBT device & Cost of device & $\begin{array}{l}\text { Clinical } \\
\text { effectiveness* }\end{array}$ & Advantages \\
\hline Condom-UBT & $\begin{array}{l}\text { US } \$ 2 \\
\text { (rupees 128) } \dagger \\
\text { Assembly components } \\
\text { commercially available }\end{array}$ & $92.3 \%$ & $\begin{array}{l}\text { Inexpensive, } \\
\text { Assembled using available resources, } \\
\text { Modified versions are used to assess blood loss } \\
\text { post insertion }\end{array}$ \\
\hline ESM-UBT & $\begin{array}{l}\text { US } \$ 6 \\
\text { (rupees 397). }{ }^{46} 47 \\
\text { Commercially not available at } \\
\text { present }\end{array}$ & $95.3 \% \ddagger$ & $\begin{array}{l}\text { Relatively inexpensive, } \\
\text { Specifically designed for PPH use, } \\
\text { All components needed for assembly available in a } \\
\text { sterile pack, } \\
\text { US-Food and Drug Administration (FDA) approved } \\
\text { device }\end{array}$ \\
\hline Bakri Balloon UBT & $\begin{array}{l}\text { US } \$ 148 \\
\text { (rupees 9554). }{ }^{48} \\
\text { Commercially available at present }\end{array}$ & $84.3 \%$ & $\begin{array}{l}\text { Ready to use, } \\
\text { Specifically designed for PPH use, } \\
\text { Comes in a sterile pack, } \\
\text { Has drainage outlet to measure ongoing blood loss, } \\
\text { US-FDA approved device }\end{array}$ \\
\hline
\end{tabular}

${ }^{*}$ Estimated from literature review of 33 studies.

†Calculated using health facility purchase lists.

¥Strength of evidence is limited, based on evidence available from three case-series studies.

ESM, Every Second Matters.

\section{Study settings}

Maternal healthcare in the Indian public system is delivered through a three-tier system. The facilities in this study were classified depending on availability of services for atonic PPH management. Primary-level care for PPH management starts at Primary Health Centers (PHC) that is equipped with skilled birth attendants and a medical officer. Secondary level is made by Community Health Centers and Sub-District Hospitals (SDH) that additionally are equipped with obstetrics-gynaecology (OBGYN) specialist, operation theatre and facilities for blood transfusion. Tertiary level comprises District Hospitals (DH) and medical colleges having additional advanced intervention and ICU facilities. ${ }^{22}{ }^{23}$ The study enrolled four public health facilities from the state of Maharashtra, India to ensure representation of all three levels of care. A convenience sample of one PHC, SDH, DH, and a tertiary medical college from Mumbai metropolitan region in Maharashtra were chosen for data collection.

\section{Data collection}

Cost data for 1-year duration from April 2017 to March 2018 were collected by adapting a validated standard tool developed for costing of health services in India. ${ }^{24}$ Cost resources were broadly classified into cost centres like human resources, infrastructure, medical equipment, non-medical equipment, drugs, consumables and utilities like electricity, water and laundry. Data on annual quantity or facility consumption for resources were obtained from sources like salary slips, departmental records, facility stock reports, patient record registers, pharmacy records, indent books, bills, statements of the accounts department, building plan of health facilities and civil department records. Source of data for each respective costing centre is reported in table 2. These data were complemented by facility surveys to further collect information on infrastructure and availability of medical and non-medical equipment. Floor area measurements were undertaken to account for area utilisation across different departments of the facility. Staff were interviewed for time allocation to assess time spent on different PPH activities as a proportion of their total working hours. A total of 16 doctors, 26 nursing staff, 5 pharmacists and 11 technical or administrative staff across chosen facilities were interviewed. As an example, all doctors were asked questions pertaining to time spent on each patient for PPH specific activities and other routine tasks like time spent in outpatient department, inpatient department (IPD), surgery, teaching, documentation and administrative services. Time spent by the senior-most doctor in performing an obstetric hysterectomy out of all routine tasks was used in costing obstetric hysterectomy procedure for eligible PPH cases. Time allocation interview findings are presented in online supplemental material 1 (online supplemental table 2).

Data on number of obstetric services like vaginal or caesarean section deliveries, number of obstetric surgeries, hysterectomies, number of blood transfusions, inpatient admissions, emergency or obstetric ICU admissions provided at respective facilities were obtained from available facility records like written registers, patient record registers, electronic health records and HMIS sources. These data were collected as facility records and HMIS indicators specifically for $\mathrm{PPH}$ were unavailable. To compute number of PPH services provided 
Table 2 Costing assumptions and apportioning

\begin{tabular}{|c|c|c|c|}
\hline Cost centre & Source of data & Numerator & Denominator \\
\hline Human resource cost & $\begin{array}{l}\text { Salary slips, departmental } \\
\text { records, time allocation } \\
\text { interview }\end{array}$ & $\begin{array}{l}\text { Proportional cost for time spent on } \\
\text { specific component of atonic PPH } \\
\text { management }\end{array}$ & Total working hours \\
\hline Area cost & $\begin{array}{l}\text { Facility survey, civil } \\
\text { department records }\end{array}$ & $\begin{array}{l}\text { Proportional cost for time spent on } \\
\text { spent on specific component of atonic } \\
\text { PPH management }\end{array}$ & $\begin{array}{l}\text { Total time spent in the } \\
\text { given facility area }\end{array}$ \\
\hline $\begin{array}{l}\text { Medical and non-medical } \\
\text { equipment cost }\end{array}$ & $\begin{array}{l}\text { Facility observations, facility } \\
\text { stock reports, }\end{array}$ & $\begin{array}{l}\text { Proportional cost for time spent on } \\
\text { specific component of atonic } \mathrm{PPH} \\
\text { management }\end{array}$ & Total working hours \\
\hline Water & $\begin{array}{l}\text { Departmental records, water } \\
\text { bills }\end{array}$ & $\begin{array}{l}\text { Proportional cost of area required for } \\
\text { specific component of atonic PPH } \\
\text { management }\end{array}$ & Total facility area \\
\hline Laundry & $\begin{array}{l}\text { Departmental records, facility } \\
\text { registers }\end{array}$ & $\begin{array}{l}\text { Proportional cost for atonic PPH } \\
\text { patients requiring laundry }\end{array}$ & $\begin{array}{l}\text { Total number of indoor } \\
\text { patients at the facility }\end{array}$ \\
\hline
\end{tabular}

$\mathrm{PPH}$, postpartum haemorrhage.

annually at each facility, event probability estimates for atonic PPH incidence in Indian settings, clinical effectiveness of three UBT devices in controlling atonic PPH bleeding (targeted literature review), probability of PPHrelated surgeries, its success rate, morbidity and $\mathrm{PPH}$ mortality rates were obtained from published literature sources. ${ }^{9} 1125-27$ Facility collected data along with Indiaspecific PPH clinical literature were used to analyse and compute unit, package and annual cost for atonic PPH management components across healthcare levels in Maharashtra, India.

\section{Data analysis}

To determine PPH events occurring at facility level, PPH incidence rate in vaginal and caesarean section deliveries were applied to facility reported deliveries to determine number of atonic PPH cases expected annually at the given facility. Proportion of atonic PPH cases uncontrolled after medical management determined number of beneficiaries eligible for UBT insertion at the facility. Clinical effectiveness parameters for each individual UBT device derived from literature review determined requirement of subsequent type and number of surgeries with each individual UBT expected at the healthcare level. Supplemental material provides PPH parameters obtained from literature along with computed number of services specific to facilities used in cost calculation (online supplemental tables 3 and 4).

Monetary value obtained from sources like salary slips, department records for human resources, civil department records for area, facility records for drugs and equipment, and departmental records, facility registers and bills for utilities were respectively attached to collected quantity of each resource utilised across cost centres. For cost analysis, resources were classified into capital and recurrent items. Capital resources were annualised using the India recommended 3\% discount rate and factoring in life expectancy and annual maintenance rate of items. ${ }^{28}$ Overall cost for services provided at the facility across cost centres was apportioned specific to atonic PPH management component by considering time or proportion calculated for atonic PPH activity being costed, number of total activities under the same category performed at facility and applying standard apportioning methods based on shared or exclusive nature of service utilisation. ${ }^{29}$ Human resource salaries were apportioned based on time allocation interviews for a given atonic PPH activity out of total working hours for all services provided. Area was apportioned based on proportional time spent for an atonic PPH activity in the given area out of all activities taking place in the same area. Drugs and consumables were apportioned as a proportion of utilisation for number of cases out of utilisation for all PPH treated patients. Medical and non-medical equipment were first annualised and then apportioned as the proportion of time used specifically for the given PPH activity out of all activities. Utilities like water and electricity were apportioned proportionally to floor area occupied for a particular service. Table 2 provides apportioning methods and corresponding data sources used in cost calculation. Online supplemental material 1 provides an 
example of apportioning methods and assumptions used in cost calculation. Worksheets were developed for cost calculation of each component at each facility followed by weighted aggregation of costs to the level of care individually for each UBT type. For example, unit condom-UBT insertion cost at DH and medical college was aggregated to get a unit condom-UBT insertion cost for tertiary level. All costs are presented in US\$ and Indian National Rupee currency. A conversion rate of US $\$ 1=64.5$ rupees for the year 2017-2018 was used. ${ }^{30}$ Data were analysed using Microsoft Excel 2016.

\section{Unit costs}

Unit costs were calculated for each component of atonic PPH management expected at the respective healthcare level. This included cost of medical management for atonic PPH, UBT insertion for refractory cases, devascularisation surgery, hysterectomy, IPD admission, ICU admission and cost of patient referral at respective levels. Denominators like number of atonic PPH cases, number of UBT eligible beneficiaries, number of referrals, number of consequential conservative or obstetric hysterectomy surgeries determined from collected data sources along with apportioned facility cost across cost centres was used to compute per beneficiary unit cost for the identified component of atonic PPH management. Unit cost of UBT insertion included the cost of UBT device. Unit cost for medical treatment, referral and IPD admission were expected to remain unaffected irrespective of the type of the UBT device used. For these services, costs were calculated only for SOC that is, management with condom-UBT device.

\section{Package costs}

To account for treatment combinations used in management of atonic PPH, treatment package costs were determined. For a certain treatment, package cost was calculated by adding unit cost associated with all treatment components for management at respective healthcare level. For all patients at primary and secondary care requiring transport, referral costs were added to get treatment package costs.

\section{Annual costs}

Unit and package cost calculation was followed by annual health system cost estimation for an annual cohort of women in Maharashtra experiencing atonic PPH after delivering in public healthcare facilities. Number of deliveries occurring across the three respective public healthcare levels in Maharashtra were combined with respective PPH service utilisation units to get pooled annual cost for a given service. Overall annual health system cost was then estimated by combining annual health system cost of medical management, further course of interventions using UBT device in uncontrolled cases and UBT training cost. Unit cost for every treatment component at each facility was first aggregated to primary, secondary and tertiary level and then applied to the annual eligible population cohort in Maharashtra to estimate annual costs with each UBT device.

Certain methodological assumptions were made during cost analysis. It was assumed that for a particular UBT device, all eligible atonic PPH cases would receive only that particular UBT across facilities. It was assumed that at primary level, all women after medical management or UBT insertion would immediately be referred for secondary care. Unit calculated cost for per day IPD or ICU admission of patients at chosen facilities were apportioned to literature based atonic PPH length of stay to estimate IPD and ICU costs for atonic PPH management. ${ }^{31-33}$ Cost of blood transfusion and other resuscitation measures were incorporated in unit costs throughout management and are not calculated separately. Training costs were estimated for one day training of healthcare providers. ${ }^{34}$ Due to time and resource limitation for primary estimation of PPH referral costs, an inflation adjusted cost of US $\$ 15.5$ (rupees 1001) per case was used from a published Indian primary economic costing study that calculated public health system cost of transportation for institutional delivery services in three districts of an Indian state. ${ }^{35} \mathrm{~B}$-Lynch suturing and stepwise devascularisation surgery in this study were considered as a single unit for cost calculation.

Probabilistic sensitivity analysis was used to address joint uncertainty effect of input parameters on costs. A beta distribution for probabilities and proportions, gamma distribution for cost and resource use was assigned to vary parameters on both sides. As drugs and consumables are procured by the government at a negotiated price whereas market prices show variation on the higher side, these were varied by $50 \%$ and $100 \%$ on lower and upper limits respectively. UBT device price was assumed to vary by $50 \%$ on both sides. Remaining parameters such as salaries, rental prices, medical and non-medical equipment, utilities and utilisation of services were varied by $25 \% .^{36}$ Monte Carlo simulations were run to obtain 1000 unit cost estimates. These estimates were used to determine 95\% CI limits for all reported costs.

\section{RESULTS}

The chosen sample of four public health facilities from Maharashtra reported 7208 vaginal and 2516 caesarean section deliveries in the year 2017-18. Of the 9724 total deliveries, 293 women were expected to experience atonic PPH. Twenty-nine out 293 cases would remain uncontrolled after medical management, thus becoming eligible for UBT device insertion. Further depending on clinical effectiveness of individual UBT device in controlling bleeding, remaining cases undergo surgical intervention depending on infrastructure and resource availability at respective clinical setting (online supplemental table 3).

\section{Unit costs}

Medical treatment of atonic PPH cases costs the health system US\$0.7 (rupees 42), US\$5 (rupees 322 ) and US\$9.4 
Table 3 Unit costs for atonic postpartum haemorrhage (PPH) management components across public health facility levels in Maharashtra, India (US $\$ 1=64.5$ rupees)

\begin{tabular}{|c|c|c|c|c|c|c|}
\hline & Medical treatment & UBT insertion & Devascularisation & Hysterectomy & $\begin{array}{l}\text { Inpatient } \\
\text { admission }\end{array}$ & ICU admission \\
\hline \multicolumn{7}{|c|}{ Per patient unit cost with condom-UBT in US\$ $(95 \% \mathrm{Cl})$} \\
\hline Primary & $\begin{array}{l}0.7 \\
(0.4 \text { to } 0.9)\end{array}$ & $\begin{array}{l}2.5 \\
(1.5 \text { to } 3.5)\end{array}$ & NA & NA & NA & NA \\
\hline Secondary & $\begin{array}{l}5.0 \\
\text { (3.5 to } 6.6)\end{array}$ & $\begin{array}{l}5.3 \\
\text { (4.1 to } 6.5)\end{array}$ & $\begin{array}{l}75.4 \\
(49.4 \text { to } 104.4)\end{array}$ & $\begin{array}{l}120.6 \\
\text { (77.9 to } 168.2)\end{array}$ & $\begin{array}{l}27.5 \\
(16.8 \text { to } 39.5)\end{array}$ & NA \\
\hline Tertiary & $\begin{array}{l}9.4 \\
(6.7 \text { to } 12.6)\end{array}$ & $\begin{array}{l}6.5 \\
(5.3 \text { to } 7.9)\end{array}$ & $\begin{array}{l}53.0 \\
(41.9 \text { to } 64.4)\end{array}$ & $\begin{array}{l}84.8 \\
\text { (66.3 to } 104.4)\end{array}$ & $\begin{array}{l}28.0 \\
(20.7 \text { to } 35.9)\end{array}$ & $\begin{array}{l}75.9 \\
\text { (50.3 to } 104.6)\end{array}$ \\
\hline \multicolumn{7}{|c|}{ Per patient unit cost with ESM-UBT in US\$ $(95 \% \mathrm{Cl})$} \\
\hline Primary & $\begin{array}{l}0.7 \\
(0.4 \text { to } 0.9)\end{array}$ & $\begin{array}{l}6.7 \\
(3.6 \text { to } 9.9)\end{array}$ & NA & NA & NA & NA \\
\hline Secondary & $\begin{array}{l}5.0 \\
(3.5 \text { to } 6.6)\end{array}$ & $\begin{array}{l}8.8 \\
(5.9 \text { to } 11.6)\end{array}$ & $\begin{array}{l}56.9 \\
\text { (37.1 to } 79.0)\end{array}$ & $\begin{array}{l}119.9 \\
(79.3 \text { to } 162.7)\end{array}$ & $\begin{array}{l}27.5 \\
\text { (16.8 to } 39.5)\end{array}$ & NA \\
\hline Tertiary & $\begin{array}{l}9.4 \\
(6.7 \text { to } 12.6)\end{array}$ & $\begin{array}{l}10.4 \\
(8.5 \text { to } 12.5)\end{array}$ & $\begin{array}{l}51.7 \\
\text { (40.6 to } 63.7)\end{array}$ & $\begin{array}{l}86.5 \\
(68.0 \text { to } 107.1)\end{array}$ & $\begin{array}{l}28.0 \\
(20.7 \text { to } 35.9)\end{array}$ & $\begin{array}{l}75.9 \\
\text { (50.3 to 104.6) }\end{array}$ \\
\hline \multicolumn{7}{|c|}{ Per patient unit cost with Bakri-UBT in US\$ $(95 \% \mathrm{CI})$} \\
\hline Primary & $\begin{array}{l}0.7 \\
(0.4 \text { to } 0.9)\end{array}$ & $\begin{array}{l}148.6 \\
\text { (74.3 to } 219.0)\end{array}$ & NA & NA & NA & NA \\
\hline Secondary & $\begin{array}{l}5.0 \\
\text { (3.5 to } 6.6)\end{array}$ & $\begin{array}{l}151.1 \\
\text { (88.0 to } 214.8 \text { ) }\end{array}$ & $\begin{array}{l}76.8 \\
\text { (51.2 to } 103.9)\end{array}$ & $\begin{array}{l}119.7 \\
\text { (80.1 to } 165.4)\end{array}$ & $\begin{array}{l}27.5 \\
(16.8 \text { to } 39.5)\end{array}$ & NA \\
\hline Tertiary & $\begin{array}{l}9.4 \\
(6.7 \text { to } 12.6)\end{array}$ & $\begin{array}{l}153.1 \\
(113.0 \text { to } 191.8)\end{array}$ & $\begin{array}{l}53.0 \\
\text { (41.6 to } 64.7)\end{array}$ & $\begin{array}{l}84.8 \\
(67.2 \text { to } 103.7)\end{array}$ & $\begin{array}{l}28.0 \\
(20.7 \text { to } 35.9)\end{array}$ & $\begin{array}{l}75.9 \\
\text { (50.3 to } 104.6)\end{array}$ \\
\hline
\end{tabular}

ICU, intensive care unit; NA, Not Applicable; UBT, uterine balloon tamponade.

(rupees 609) per patient at primary, secondary and tertiary levels respectively. For uncontrolled cases requiring further intervention, condom-UBT (SOC) insertion costs US\$2.5 (rupees 160), US $\$ 5.3$ (rupees 339) and US\$6.5 (rupees 422) at the three respective levels. Devascularisation group of surgeries for uncontrolled cases after condom-UBT insertion costs US $\$ 75.4$ (rupees 4864 ) per case at secondary and US $\$ 53.0$ (rupees 3419 ) per case at tertiary level. Similarly, hysterectomy procedure costs US $\$ 120.6$ (rupees 7782) per case at secondary and US\$84.8 (rupees 5471) at tertiary level. Table 3 provides the health system unit costs with condom-UBT, ESM-UBT and Bakri-UBT. IPD admission for an atonic PPH case costs the health system US $\$ 27.5$ (rupees 1776 ) per patient at secondary and US $\$ 28.0$ (rupees 1806) per patient at tertiary level. ICU admission at tertiary facility costs the health system US $\$ 76.0$ (rupees 4902 ) per patient getting admitted for atonic PPH management. One-time training of medical officers and OBGYN specialists across public health facilities of Maharashtra costs US\$12.1 (rupees 778) per eligible atonic PPH case needing UBT device insertion.

\section{Package cost}

Of the eligible cases, condom-UBT successfully controls 92.3\% cases after device insertion and ongoing medical and resuscitation measures. This combination treatment costs the health system a total of US $\$ 46.2$ (rupees 2979),
US\$ 37.8 (rupees 2437) and US\$44.0 (rupees 2838) at three respective levels. This treatment package comprises costs of medical management, UBT insertion, IPD admission and additional referral cost for primary care patients. Treatment package cost for control with devascularisation surgery after condom-UBT insertion and medical treatment has a total health system cost of US $\$ 113.2$ (rupees 7301) and US $\$ 97.0$ (rupees 6256) per patient at secondary and tertiary levels respectively. Similarly, a direct hysterectomy for uncontrolled atonic PPH after condom-UBT insertion costs US $\$ 158.4$ (rupees 10 218) and US $\$ 128.8$ (rupees 8308) at secondary and tertiary levels, respectively. Less than $4 \%$ of the uncontrolled atonic PPH cases with condom-UBT insertion are expected to require ICU facility for atonic PPH management. Health system package costs for such treatment combinations can be derived from the given unit cost table. Alternatively, if ESM or Bakri-UBT device is used in controlling atonic $\mathrm{PPH}$, package cost varies on account of device effectiveness and associated resource use. Table 4 lists treatment package cost estimates for atonic PPH management with three UBT devices.

\section{Annual costs}

Annual cost to the public health system was estimated for managing 27915 women experiencing atonic PPH annually out of the 969264 deliveries reported by the state of Maharashtra for the year 2017-2018. ${ }^{37}$ The estimated 
Table 4 Treatment package cost for atonic postpartum haemorrhage (PPH) management across public healthcare levels in Maharashtra, India (US $\$ 1=64.5$ rupees) $(95 \% \mathrm{Cl})$

\begin{tabular}{|c|c|c|c|}
\hline & Condom-UBT & ESM-UBT & Bakri-UBT \\
\hline \multicolumn{4}{|c|}{ Package cost for atonic PPH controlled after UBT insertion in US\$ (95\% Cl) } \\
\hline Primary & $\begin{array}{l}46.2 \\
\text { (34.9 to } 59.1 \text { ) }\end{array}$ & $\begin{array}{l}50.4 \\
\text { (38.5 to } 63.8)\end{array}$ & $\begin{array}{l}192.3 \\
\text { (153.8 to 230.8) }\end{array}$ \\
\hline Secondary & $\begin{array}{l}37.8 \\
\text { (28.5 to } 48.3)\end{array}$ & $\begin{array}{l}41.3 \\
\text { (31.9 to } 52.0)\end{array}$ & $\begin{array}{l}184.1 \\
\text { (147.0 to } 222.4)\end{array}$ \\
\hline Tertiary & $\begin{array}{l}43.9 \\
\text { (35.4 to } 53.3 \text { ) }\end{array}$ & $\begin{array}{l}47.9 \\
\text { (39.6 to } 57.0)\end{array}$ & $\begin{array}{l}190.5 \\
\text { (149.9 to 233.2) }\end{array}$ \\
\hline \multicolumn{4}{|c|}{ Package cost for atonic PPH controlled with devascularisation surgery after UBT failure in US\$ $(95 \% \mathrm{Cl})$} \\
\hline Secondary & $\begin{array}{l}113.2 \\
(103.2 \text { to } 123.8)\end{array}$ & $\begin{array}{l}98.2 \\
\text { (88.5 to } 108.7)\end{array}$ & $\begin{array}{l}260.9 \\
\text { (218.6 to } 304.2 \text { ) }\end{array}$ \\
\hline Tertiary & $\begin{array}{l}96.9 \\
\text { (88.7 to } 106.3)\end{array}$ & $\begin{array}{l}99.6 \\
\text { (91.4 to } 109.3 \text { ) }\end{array}$ & $\begin{array}{l}243.5 \\
\text { (202.2 to 286.9) }\end{array}$ \\
\hline \multicolumn{4}{|c|}{ Package cost for atonic PPH controlled with direct hysterectomy after UBT failure in US\$ (95\% Cl) } \\
\hline Secondary & $\begin{array}{l}158.4 \\
(149.6 \text { to } 168.9)\end{array}$ & $\begin{array}{l}161.1 \\
(152.1 \text { to } 171.7)\end{array}$ & $\begin{array}{l}303.8 \\
\text { (256.0 to } 355.6 \text { ) }\end{array}$ \\
\hline Tertiary & $\begin{array}{l}128.8 \\
(120.5 \text { to } 138.6)\end{array}$ & $\begin{array}{l}134.4 \\
(126.2 \text { to } 144.0)\end{array}$ & $\begin{array}{l}275.3 \\
\text { (231.2 to } 319.1)\end{array}$ \\
\hline
\end{tabular}

ESM, Every Second Matters; UBT, uterine balloon tamponade.

annual cost of overall medical management for atonic PPH was US\$1 032647 (rupees 66605750 ) or US\$36.9 (rupees 2386) per atonic PPH patient. Additionally, 2791 women were estimated to require UBT intervention followed by devascularisation surgery, hysterectomy or ICU facility for uncontrolled cases. The annual cost of managing these uncontrolled cases in public health facilities of Maharashtra, India is US\$193 963 (rupees 12510 610) with condom-UBT, US\$188 090 (rupees 12131 800) with ESMUBT and US\$620 297 (rupees 40009 169) with Bakri-UBT when used for medically uncontrolled atonic PPH cases.
This corresponds to a per eligible beneficiary cost of US $\$ 69.5$ (rupees 4482 ) for control with condom-UBT and subsequent interventions, US\$67.4 (rupees 4346) for ESMUBT and US\$222.2 (rupees 14 333) for Bakri-UBT, respectively. Overall, the health system incurs a per atonic PPH patient management cost of US\$43.9 (rupees 2834) with condom-UBT, US $\$ 43.7$ (rupees 2820) with ESM-UBT and US $\$ 59.2$ (rupees 3819 ) per case with Bakri-UBT if made available for atonic PPH management in Maharashtra, India. Table 5 describes the annual health system cost of atonic PPH management in Maharashtra, India.

Table 5 Annual public health system cost of managing atonic postpartum haemorrhage (PPH) using three uterine balloon tamponade (UBT) devices in Maharashtra, India (US\$1=64.5 rupees) (95\% CI)

\begin{tabular}{|c|c|c|c|}
\hline Cost centre & $\begin{array}{l}\text { Condom-UBT } \\
\text { US\$ (95\% Cl) }\end{array}$ & $\begin{array}{l}\text { ESM-UBT } \\
\text { US\$ ( } 95 \% \mathrm{CI})\end{array}$ & $\begin{array}{l}\text { Bakri-UBT } \\
\text { US\$ (95\% CI) }\end{array}$ \\
\hline Annual atonic PPH medical management cost (a) & \multicolumn{3}{|c|}{1032647 (688893 to 1375716$)$} \\
\hline $\begin{array}{l}\text { Annual cost for uncontrolled atonic PPH } \\
\text { cases managed with UBT device and surgical } \\
\text { interventions (c) }\end{array}$ & $\begin{array}{l}193963 \\
(152772 \text { to } 232481)\end{array}$ & $\begin{array}{l}188090 \\
(150393 \text { to } 226901)\end{array}$ & $\begin{array}{l}620297 \\
(386981 \text { to } 857415)\end{array}$ \\
\hline Annual UBT device cost & $\begin{array}{l}5540 \\
(2362 \text { to } 8664)\end{array}$ & $\begin{array}{l}17182 \\
(7324 \text { to } 26770)\end{array}$ & $\begin{array}{l}413485 \\
(180326 \text { to } 652695)\end{array}$ \\
\hline $\begin{array}{l}\text { Per patient cost of medical management for } \\
\text { atonic PPH }\end{array}$ & 36.9 (29 to 45$)$ & & \\
\hline
\end{tabular}




\section{DISCUSSION}

To our knowledge, this is the first study comprehensively assessing public health system cost associated with atonic PPH management in India. A study conducted in Myanmar at a 25 bedded hospital reported cost of PPH management along with other obstetric complications. ${ }^{38}$ Similarly, an Egypt study reported estimates of direct health system costs for different procedures used in PPH management at two DHs. ${ }^{39}$ Our study specifically estimates primary health system cost for managing atonic PPH across healthcare levels in the Indian public health system. This study focused on estimating the cost of using different UBT devices given their varying reported clinical effectiveness in controlling atonic PPH bleeding. Additionally, we have undertaken costing for medical management, and surgical intervention subsequent to failed UBT treatment across public healthcare levels in India.

Our analysis reported a total cost of US $\$ 43.9(95 \%$ CI 36 to 53) per atonic PPH patient with condom-UBT, US $\$ 43.7$ (95\% CI 35 to 52) with ESM-UBT and US\$59.2 (95\% CI 46 to 73 ) with Bakri-UBT use in Maharashtra's public health system for the year 2017-2018. The study from Myanmar reported an inflation adjusted unit cost of US\$28 $( \pm 1.61)$ per case for managing $\mathrm{PPH}$ in their hospital study setting. ${ }^{40}$ The Egypt study reported an adjusted treatment cost of US $\$ 110$ per case for $\mathrm{PPH}$ but reported use of UBT intervention in $3.9 \%$ cases as compared with $9.9 \%$ in our study. As primary data were not available, the assumption that all those needing UBT intervention would receive it may be one of the reasons for lower unit costs in our study as UBT intervention would reduce subsequent surgical interventions. Neither of the two studies reported UBT intervention costs specifically.

The unit cost of overall medical management for an atonic PPH case in our study was US\$36.9 (rupees 2386). Unit cost of UBT device insertion increased gradually with higher facility levels and was dominated by cost of the UBT device itself. Treatment package costs for UBT insertion at primary level included referral cost and hence reported higher costs as compared to secondary or tertiary level. Unit and package costs for surgical intervention subsequent to UBT failure was found to be higher at secondary level as compared with tertiary level in our study. Tertiary level hysterectomy cost at US $\$ 84.8$ (rupees 5471) per case in our study is in similar range as reported by another Indian study at an adjusted cost of US $\$ 95.7$ (rupees 6174 ) for a DH. ${ }^{41}$ Likewise, stepwise devascularisation surgery in the Egypt study reported an adjusted cost of US $\$ 62$ per case is in the similar range to those reported in our findings. Unit and package surgical costs in our study also varied depending on clinical effectiveness of UBT device affecting consumption of facility resources. Cost of condom-UBT device in Indian public health facilities was US\$1.9 (rupees 128), one-third the price of ESM-UBT device. Bakri balloon at a market price of US $\$ 148$ (rupees 9554) in India costs significantly higher in comparison to the other two devices. Bakri-UBT at a higher price and lower reported clinical effectiveness in controlling atonic PPH, accounted for higher unfavourable unit and package costs in our analysis. ESMUBT reported a marginally higher clinical effectiveness but had a three-time higher device cost as compared with condom-UBT. The unit health system cost however for both condom and ESM-UBT was similar at US\$43.9 (rupees 2834) and US\$43.7 (rupees 2820).

Cost of medical management for atonic PPH across healthcare levels in this study constitutes a major component of the annual costs $(84.2 \%$ for condom-UBT, $84.6 \%$ for ESM-UBT and $62.5 \%$ for Bakri-UBT). This is expected as majority patients are controlled with uterotonics and supportive measures. Remaining portion of annual costs are accounted by UBT and subsequent interventions for uncontrolled cases $(15.8 \%$ for condom-UBT, $15.4 \%$ for ESM-UBT and $37.5 \%$ for Bakri-UBT). Both condom and ESM-UBT have lower unit, package and annual costs as compared with Bakri-UBT. However, strength of clinical effectiveness evidence available for ESM-UBT at the time of this study was limited to a few case series studies reporting survival rates. ${ }^{202142}$ Cost implication of using ESM-UBT device would vary if higher quality of clinical effectiveness evidence across UBT devices along with procurement cost of equipping all Indian public health facilities with a particular device is made available. Cost of UBT device accounted to $0.5 \%$ of the annual health system costs for condom-UBT, $1.4 \%$ for ESM-UBT and $25 \%$ for Bakri-UBT, respectively.

The state of Maharashtra in the year 2017-2018 spent an estimated US\$1 $226 \quad 610$ (rupees 79116 359) by catering to all atonic PPH cases in public health facilities with condom-UBT intervention as per the recommended treatment guidelines. Alternatively, if ESM-UBT or Bakri balloon was available, the state would spend US\$1 220 737 (rupees 78737549 ) or US\$1 652944 (rupees 106 614 919) respectively. Atonic PPH management with condom-UBT in Maharashtra thus accounted to $3.8 \%$ of the annual state spending on reproductive and child health (RCH) activities in the year 2017-2018. ${ }^{43}$ ESMUBT would account to a similar $3.8 \%$ whereas Bakri-UBT for atonic PPH management would account to a higher $5.2 \%$ of the state's annual RCH spending.

This study empirically derived costs of atonic PPH management across public healthcare levels for a state in India. The WHO guideline development group has identified use of UBT in PPH as a research priority. ${ }^{12}$ Our study provides economic evidence for equipping health systems with the choice of a clinically effective UBT intervention that is affordable and suitable for low resource settings like India. Findings of this study can be used to optimise efficiency by improving financial allocation within the health system. Under the revised Janani Shishu Suraksha Karyakaram scheme in India, pregnant women accessing public health facilities are entitled to free treatment for childbirth and pregnancy complications. ${ }^{44}$ Implementation under the PMJAY scheme has revised high risk and caesarean section delivery package costs to US\$178 
(rupees 11 500). This package is inclusive of drugs, diagnostics, consultations, procedures, stay and food for patients availing care. ${ }^{45}$ The results from our study can be used to address package costs for the postpartum PPH complication across different publicly financed health schemes to avoid any financial burden on beneficiaries as reported for institutional deliveries in India. ${ }^{19}$

\section{Limitations}

The study bases its cost findings from one region of Maharashtra by collecting data from sample facilities across healthcare levels. Given the differences within districts across the state, provisioning and utilisation of healthcare services vary on account of socioeconomic, epidemiological and other contextual factors. Although we have undertaken uncertainty analysis to address these factors to an extent, generalisability of the study results across states of India may be difficult. For analysis, it was assumed that all atonic PPH cases requiring UBT intervention will receive it and a uniform UBT device would be available across all facilities. However, in practice, this might differ resulting in deviation of cost estimates from those reported. Facility-level disaggregated HMIS data on PPH and corresponding service utilisation were not available, so we had to rely on literature-based probabilities to derive PPH service utilisation for costing.

\section{CONCLUSION}

The study provides health system cost of managing atonic PPH complication in Indian public health settings. Policy-makers can use these findings to include the clinical condition of PPH to treatment benefit packages under publicly financed health schemes and to inform budgetary allocations to equip the Indian health system with a suitable UBT choice. Economic evaluation studies can use this evidence to determine the most cost-effective UBT choice for Indian settings. In addition to equipping facilities and supply lines with the right commodities, programmes must optimise performance of the healthcare providers and ensure efficient referral systems are in place to save a woman's life.

Acknowledgements The authors acknowledge the support provided by the Department of Health Research (DHR), MOHFW, Government of India. They are grateful to Dr Dinesh Baswal (Deputy Commissioner Maternal Health Division, MOHFW, India) for suggesting the topic to HTAln and Dr Smita Mahale (Director, NIRRH-ICMR, Mumbai, India) for her encouragement and support. They acknowledge the technical support provided by HTAln, DHR and the project staff at the institute. They are grateful for the inputs provided by experts Dr Niranjan Maydeo (Professor and Head, Department of Obstetrics and Gynecology, King Edward Memorial Hospital, Mumbai, India), Mr Pankaj Bahuguna (Economic Evaluation Specialist, School of Public Health, PGIMER), Dr Anushree Patil (Scientist E, Clinical Research, NIRRH-ICMR, Mumbai, India), Dr. Amita Pandey (Professor, Department of Obstetrics and Gynecology, King George's Medical University, Lucknow, India), Dr Vanita Suri (Professor and Head, Department of Obstetrics and Gynecology, Postgraduate Institute of Medical Education and Research, Chandigarh, India) and Dr Amit Patel (Program Director, Jivdaya Foundation, Texas, United States of America).

Contributors BNJ, SSS and KVM were responsible for conceptualisation and design of the study. KVM and HC undertook data collection. SS and KVM analysed the data. BNJ checked the analysis and edited the manuscript. SSS was responsible for the first draft and all authors contributed to further revisions. All authors read and approved the final manuscript.

Funding This work was supported by HTAln, Department of Health Research, Ministry of Health and Family Welfare, Government of India grant number T.11011/02/2017-HR.

Competing interests None declared.

Patient consent for publication Not required.

Ethics approval The study was approved by the NIRRH Ethics Committee for Clinical Studies (Approval number: D/ICEC/Sci-29/31/2018).

Provenance and peer review Not commissioned; externally peer reviewed.

Data availability statement Data are available upon reasonable request. All unpublished data are available upon reasonable request to the corresponding author BJ through email.

Supplemental material This content has been supplied by the author(s). It has not been vetted by BMJ Publishing Group Limited (BMJ) and may not have been peer-reviewed. Any opinions or recommendations discussed are solely those of the author(s) and are not endorsed by BMJ. BMJ disclaims all liability and responsibility arising from any reliance placed on the content. Where the content includes any translated material, BMJ does not warrant the accuracy and reliability of the translations (including but not limited to local regulations, clinical guidelines, terminology, drug names and drug dosages), and is not responsible for any error and/or omissions arising from translation and adaptation or otherwise.

Open access This is an open access article distributed in accordance with the Creative Commons Attribution Non Commercial (CC BY-NC 4.0) license, which permits others to distribute, remix, adapt, build upon this work non-commercially, and license their derivative works on different terms, provided the original work is properly cited, appropriate credit is given, any changes made indicated, and the use is non-commercial. See: http://creativecommons.org/licenses/by-nc/4.0/.

\section{ORCID iDs}

Siddesh Sitaram Shetty http://orcid.org/0000-0003-0696-1622

Kusum Venkobrao Moray http://orcid.org/0000-0002-9333-5672

Himanshu Chaurasia http://orcid.org/0000-0003-3679-4415

Beena Nitin Joshi http://orcid.org/0000-0003-2187-4922

\section{REFERENCES}

1 Onarheim $\mathrm{KH}$, Iversen $\mathrm{JH}$, Bloom DE. Economic benefits of investing in women's health: a systematic review. PLoS One 2016;11:e0150120-3.

2 Amiri A, Gerdtham U. Impact of maternal and child health on economic growth: new evidence based granger causality and DEA analysis. Sweden: Partnersh Matern Newborn Child Heal (PMNCH), World Heal Organ, 2013: 1-30.

3 Registrar General of India. Special BULLETIN on maternal mortality in India 2015-17 sample registration system office of registrar general, India, 2019. Available: http://www.censusindia.gov.in

4 Singh PK. India has achieved groundbreaking success in reducing maternal mortality. WHO reg. off. south-east Asia, 2016. Available: https://www.who.int/southeastasia/news/detail/10-06-2018-indiahas-achieved-groundbreaking-success-in-reducing-maternalmortality

5 DGHS. National health profile 201813 th issue, 2018. Available: www.who.int/classifications

6 The World Bank. Number of maternal deaths | data, 2015. Available: https://data.worldbank.org/indicator/SH.MMR.DTHS?most_recent_ value desc=true

7 Health and family welfare statistics in India 2017. India Ministry of Health and Family Welfare, Government of India, 2017. Available: https://nrhm-mis.nic.in/PubStatistical_Publications/Family\% 20Welfare\%20Statistics\%20in\%20India/FW\%20Statistics\%20in\% 20India\%202017.pdf

8 Say L, Chou D, Gemmill A, et al. Global causes of maternal death: a who systematic analysis. The Lancet Global Health 2014;2:e323-33.

9 Rastogi A Z. Postpartum haemorrhage | National health portal of India. Natl. heal. portal India, 2017. Available: https://www.nhp.gov. in/disease/gynaecology-and-obstetrics/postpartum-haemorrhage

10 Dutta D. Textbook of obstetrics. 46. 8. India: Jaypee Brothers Medical Publishers (P) Ltd, 2015.

11 Guidelines- MH. National Health Mission, 2020. Available: https:// nhm.gov.in/index1.php?lang=1\&level=3\&sublinkid=839\&lid=377 
12 Dept. of Reproductive Health and Research W. WHO recommendations for the prevention and treatment of postpartum haemorrhage, 2012. Available: www.who.int/maternal_child_ adolescent

13 Suarez S, Conde-Agudelo A, Borovac-Pinheiro A, et al. Uterine balloon tamponade for the treatment of postpartum hemorrhage: a systematic review and meta-analysis. Am J Obstet Gynecol 2020;222:293.e1-293.e52.

14 Division MH, Welfare F. Guidance note on prevention and management of postpartum haemorrhage. India Ministry of Health and Family Welfare, Government of India; 2015: 1-28. https://www. nhm.gov.in/images/pdf/programmes/maternal-health/guidelines/ Guidance_Note_on_Prevention_\&_Management_of_Postpartum_ Haemorrhage.pdf

15 Maternal Health - Jiv Daya Foundation. India maternal health Initiative, 2020. Available: https://www.jivdayafound.org/maternalhealth

16 MGIMS. Govt of India, NHSRC and Harvard discuss PPH management, 2020. Available: https://www.mgims.ac.in/index.php/ component/easyblog/392-govt-of-india-discusses-the-managementof-pph-at-mgims? Itemid=1

17 The Hitavada. 'Harvard' helps State's 11 medical colleges to reduce maternal deaths due to PPH - The Hitavada, 2020. Available: https:// www.thehitavada.com/Encyc/2020/3/3/-Harvard-helps-State-s-11medical-colleges-to-reduce-maternal-deaths-due-to-PPH.html

18 Mishra S, Mohanty SK. Out-Of-Pocket expenditure and distress financing on institutional delivery in India. Int $J$ Equity Health 2019;18:99.

19 Ramanathan A, Eckardt MJ, Nelson BD, et al. Safety of a condom uterine balloon tamponade (ESM-UBT) device for uncontrolled primary postpartum hemorrhage among facilities in Kenya and Sierra Leone. BMC Pregnancy Childbirth 2018;18:1-7.

20 Burke TF, Danso-Bamfo S, Guha M, et al. Shock progression and survival after use of a condom uterine balloon tamponade package in women with uncontrolled postpartum hemorrhage. Int $J$ Gynaecol Obstet 2017:139:34-8.

21 Mollazadeh-Moghaddam K, Dundek M, Bellare A, et al. Mechanical properties of the every second matters for Mothers-Uterine balloon tamponade (ESM-UBT) device: in vitro tests. AJP Rep 2019;9:e376-83.

22 MOHFW G of I. Indian public health standards: National health mission, 2007. Available: https://nhm.gov.in/index1.php?lang=1\& level $=2 \&$ sublinkid $=971 \&$ lid $=154$

23 National Rural Health Mission. Operational guidelines on maternal and newborn health. India Ministry of Health and Family Welfare, Government of India; 2009. http://nhsrcindia.org/sites/default/files/ Operational\%20Guidelines\%20for\%20Maternal\%20\%20Newborn\% 20Health.pdf

24 Department of Community Medcine and School of Public Health PGIMER Chandigarh. Costing methodology, 2018. Available: https:// www.healtheconomics.pgisph.in/costing_web/index.php?action= costing_method

25 Carroli G, Cuesta C, Abalos E, et al. Epidemiology of postpartum haemorrhage: a systematic review. Best Pract Res Clin Obstet Gynaecol 2008;22:999-1012.

26 Aderoba AK, Olagbuji BN, Akintan AL, et al. Condom-catheter tamponade for the treatment of postpartum haemorrhage and factors associated with success: a prospective observational study. BJOG 2017;124:1764-71.

27 Tasneem F, Sirsam S, Shanbhag V. Clinical study of post partum haemorrhage from a teaching hospital in Maharashtra, India. Int $J$ Reprod Contracept Obstet Gynecol 2017;6:2366.

28 Department of Health Research. Health technology assessment in India a manual, 2018. Available: https://dhr.gov.in/

29 Fox-Rushby J, Cairns J. Economic evaluation - Fox-Rushby, Julia, Cairns, John. Google books, 2005. Available: https://books.google. co.in/books?hl=en\&lr=\&id=tczsAAAAQBAJ\&oi=fnd\&pg=PP1\&ots=
aLtLUeEFMB\&sig=qfpRBjI0MdWxUHK1ZilWTrX91FE\&redir_esc=y\# $\mathrm{v}=$ onepage\&q\&f=false

30 Venugopal P, Indicators WD. The world bank. Manag Labour Stud 1997;1999:135-6.

31 Marshall AL, Durani U, Bartley A, et al. The impact of postpartum hemorrhage on hospital length of stay and inpatient mortality: a National Inpatient Sample-based analysis. Am J Obstet Gynecol 2017;217:344.e1-344.e6.

32 Joseph CM, Bhatia G, Abraham V, et al. Obstetric admissions to tertiary level intensive care unit - Prevalence, clinical characteristics and outcomes. Indian J Anaesth 2018;62:940-4.

33 Kumar P, Dhillon P. Length of stay after childbirth in India: a comparative study of public and private health institutions. $B M C$ Pregnancy Childbirth 2020;20:181.

34 Ministry of Health and Family Welfare (Government of India). National health profile (NHP) of India- 2018: central Bureau of health intelligence, 2018. Available: https://www.cbhidghs.nic.in/index1. php?lang $=1$ \&level $=2 \&$ sublinkid $=88 \&$ lid $=1138$

35 Prinja S, Manchanda N, Aggarwal AK, et al. Cost \& efficiency evaluation of a publicly financed \& publicly delivered referral transport service model in three districts of Haryana State, India. Indian J Med Res 2013;138:1003-11.

36 Chauhan AS, Prinja S, Ghoshal S, et al. Cost of treatment for head and neck cancer in India. PLoS One 2018;13:e0191132-13.

37 State fact sheet: FY 2018-2019 (April-March) Maharashtra key indicators, 2019. Health management information systemMinistry of Health and Family Welfare, Government of India. Available: https:// nrhm-mis.nic.in/hmisreports/frmstandard_reports.aspx

38 Shwe ATW, Riewpaiboon A, Chaikledkaew U, et al. Treatment cost and costing model of obstetric complications at a hospital in Myanmar. PLoS One 2019;14:e0213141.

39 Vlassoff M, Abdalla HA, Gor V. The cost to the health system of postpartum hemorrhage in Egypt key points, 2016. Available: www. guttmacher.org

40 CPI inflation calculator. U.S. Bureau of labor statistics, 2016. Available: https://data.bls.gov/cgi-bin/cpicalc.pl?cost1=27.04\& year $1=201506 \&$ year2 $=201706$

41 Chatterjee S, Laxminarayan R. Costs of surgical procedures in Indian hospitals. BMJ Open 2013;3. doi:10.1136/bmjopen-2013-002844. [Epub ahead of print: 20 Jun 2013].

42 Nampoothiri NJ. NHM in Maharashtra: budget trends 2015-16 to 2018-19. India: National Centre for Advocacy Studies, 2018. Available: http://ncasindia.org/wp-content/pdf/pub/pb/NHM_ Publication.pdf

43 National Health Mission, Ministry of Health and Family Welfare, Government of India. National urban health mission: National health mission; 12, 2020. Available: https://nhm.gov.in/index1.php?lang=1\& level=1\&sublinkid $=970 \&$ lid $=137$

44 NavjaatShishu Suraksha Karyakram (NSSK). National health mission, 2020. Available: https://nhm.gov.in/index1.php?lang=1\&level=3\& sublinkid $=842 \&$ lid $=308$

45 Ayushman Bharat, National Health Authority. Documents, 2020. Available: https://www.pmjay.gov.in/resources/documents

46 Massachusetts General Hospital. Every second matters for Mothers and babies - Uterine balloon tamponade for postpartum hemorrhage. Massachusetts Gen. Hosp. Emerg. Med, 2018. Available: https://www.massgeneral.org/emergency-medicine/ global-health/initiatives-and-programs/every-second-matters-formothers-and-babies-uterine-balloon-tamponade-for-postpartumhemorrhage

47 Burke TF, Ahn R, Nelson BD, et al. A postpartum haemorrhage package with condom uterine balloon tamponade: a prospective multi-centre case series in Kenya, Sierra Leone, Senegal, and Nepal. BJOG 2016:123:1532-40.

48 Bakri Balloon. Packaging type: box, RS 9500 /pack Gyno care services | ID: 18666858655, 2020. Available: https://www.indiamart. $\mathrm{com} / \mathrm{proddetail/bakri-balloon-18666858655.html}$ 